\title{
Shoulder ganglion cysts in MRI: accompanying tendon pathologies and
}

\section{labral lesions}

\section{Mehmet Hamdi Sahan ${ }^{1 *}$}

\begin{abstract}
Objective: The aim of this study was to investigate shoulder tendon pathologies and labral lesions that accompanied with ganglion cysts on the shoulder via magnetic resonance imaging (MRI).

Material and Methods: The 893 shoulder MRIs registered in our computer automation system were reviewed retrospectively between January 2014 and December 2018. Thirty-two patients who ganglion cysts observed in three different localizations in MRI were included to our study. Three group were defined as spinoglenoid notch (1st group), paralabral (2nd group), supra acromioclavicular joint (3rd group). The cases age, gender, clinical findings, localization, size and accompanying pathologies were classified. Rotator cuff tendons, the long head of the biceps tendon pathologies and labral lesions were examined.
\end{abstract}

Results: A total of 32 patients were 16 males (mean age $49 \pm 15$ years) and 16 females (mean age $54.7 \pm 14$ years). Groups were consisted 15 cases in 1st group, 12 cases in 2 nd group and 5 cases in 3rd group. In all groups with ganglion cysts, rotator cuff pathologies were frequently accompanied. There was no a significant difference between the groups in terms of rotator cuff pathologies ( $p>0.05$ ). Entrapment neuropathy in group 1, the long head of the biceps tendon and labral lesions in group 2 were frequently associated. This association was statistically significant among the groups. Largesized cysts were observed in group 3. There was a positive correlation between cyst size and the number of accompanying pathologies in the 1 st and 2nd groups (r:0.582, p:0.001).

Conclusion: In symptomatic shoulder ganglion cysts, understanding ganglion cysts, knowing the pathologies accompanied with ganglion cysts may be useful for surgical plan of cases.

Key words: Shoulder, ganglion cysts, rotator cuff, magnetic resonance imaging

\section{Introduction}

Among the causes of shoulder pain and dysfunction the ganglion cysts are rare (1). Ganglion cysts are cystic formations on the joint and tendon sheaths, which are formed by the herniation of their synovia (2-4). Rarely, they can also arise from tendon fibrils $(3,4)$. Ganglion cysts, occurs between 30-50 years of age and mostly among the women. It is not always associated with trauma (3).

Although it is most commonly appear in hands and wrists, it may be seen less frequently in the proximal tibiofibular joint, in the posterior of the knee as baker cyst, in the ankles (2). Ganglion cysts in the shoulder are rarely encountered.
Understanding ganglion cysts may be useful in the surgical plan of the cases. In the literature, there are a few case reports about spinoglenoid notch, paralabral and supra acromioclavicular joint ganglion cysts $(1,5-11)$.

However, to the best of our knowledge, there has been no work in the previous literature that has investigated the pathologies accompanied with ganglion cysts.

In this study, it was aimed to investigate labral lesions and shoulder tendon pathologies associated with ganglion cysts detected in spinoglenoid notch, paralabral and supra acromioclavicular joints in magnetic resonance imaging (MRI). 


\section{Material and Methods}

\section{Study population and exclusion criteria}

The 893 shoulder MRIs registered in our computer automation system were reviewed retrospectively between January 2014 and December 2018. Thirty-two patients older than 18 years who had ganglion cysts in three different localizations in MRI were included into the study. Patients were divided into three group as spinoglenoid notch (1st group) (Figure 1), paralabral (2nd group) (Figure 2) and supra acromioclavicular joint (3rd group) (Figure 3). Patients with ganglion cysts who complained of shoulder pain and dysfunction, clinically evaluated tendon pathology and/or shoulder swelling were included in the study. The cases were classified as age, gender, clinical findings, localization, size and accompanying pathologies.

In the shoulder joint; patients with recurrent dislocation, operation, trauma, osteoarthritis and mass were excluded from the study. Patients with known malignancy and metastatic suspicions were also excluded from the study. The study was conducted in compliance with the Helsinki Declaration and was approved by the hospital Ethics Committee.

\section{MRI examination and interpretation}

Magnetic Resonance Image (MRI) of patients were collected with 1.5 Tesla MRI device (Philips MRI Systems, Achieva Release 3.2 Level 2013-10-21, Philips Medical Systems Nederland B.V) using the surface shoulder coil. In the examination, T1 weighted; T1-TSE (Turbo Spin-Echo) axial, T1-TSE oblique coronal (780/15; FOV 14 cm; crosssectional thickness $3.5 \mathrm{~mm}$; intersection gaps $0.4 \mathrm{~mm}$; matrix $320 \times 256$ ), T2 weighted; T2-FFE (Fast-Field Echo) axial, T2-TSE oblique sagittal, T2 weighted fat-suppressed, T2-SPAIR (spectral attenuated inversion recovery) axial and oblique coronal (3400/50; FOV, $14 \mathrm{~cm}$; cross-sectional thickness $3.5 \mathrm{~cm}$; intersection gaps $0.4 \mathrm{~mm}$; matrix, $256 \times$ 256) images were obtained.

Ganglion cysts were defined as round or oval with low signal intensity on T1-weighted images and high signal intensity on T2-weighted images. The cysts were classified and evaluated in a single center in two different pulse sequences and two different image planes. The size of ganglion cysts was measured from the most prominent cross section to the largest diameter. Rotator cuff tendons, the long head of the biceps tendon pathologies and labral lesions were examined. Tendon pathologies were evaluated due to full-thickness, partial tear and tendinitis-tendinosis. Labral lesions were also evaluated. The number of accompanying pathologies was recorded in cases with ganglion cysts. All MRIs were examined by an musculoskeletal system experienced radiologist.

\section{Statistical analysis}

Statistical analyses were performed using SPSS version 20 software (SPSS, Chicago, IL, U.S.A). Data are expressed as mean \pm standard deviation (SD) or median (range). Categorical variables were compared between groups with the chi-square test. The groups showed normal distribution and the variances were homogeneous. One-way ANOVA was used to assess differences of cystic groups. For binary comparisons, Tukey post hoc analysis was done. Pearson correlation analysis was performed to statistical comparison of age and the number of accompanying pathologies, cyst size and the number of accompanying pathologies. $\mathrm{P}<0.05$ was considered statistically significant.

\section{Results}

The 16 male (mean age $49 \pm 15$ years, range $21-70$ ) and 16 female patients were subjected to study (mean age $54.7 \pm 14$ years, range 32-76). Group 1 consisted of 15 cases (Figure 1), group 2, 12 cases (Figure 2) and group 3, 5 cases (Figure 3). Table 1 shows demographic characteristics and accompanied pathologies of ganglion cyst groups.

In group 1, 13 of 15 cases had rotator cuff tendon pathology; 2 case of rotator cuff tendons was normal. Rotator cuff tendon pathologies; In 4 cases, supraspinatus tendon was full-thickness tear, in 6 cases partial tear and in 3 cases tendinitis-tendinosis was detected. There were also partial tears in the subscapularis tendon in 3 cases and in the infraspinatus tendon in 1 case.

In group 2, 11 of 12 cases had rotator cuff tendon pathology; 1 case of rotator cuff tendons was normal. Rotator cuff tendon pathologies; in 4 cases, supraspinatus tendon was full-thickness tear, 5 cases were partial tear and 2 cases were tendinitis-tendinosis. There were also partial tears in the subscapularis tendon in 2 cases and infraspinatus tendon in 1 case.

In group 3, rotator cuff tendon pathology is present in 5 of 5 cases. In 3 cases, full-thickness tear of the supraspinatus tendon and partial tear of 2 cases were detected. There were also partial tears in the subscapularis tendon in 1 case.

In group 2, the long head of the biceps tendon pathology in 9 cases and labral lesion in 10 cases were present. Two case had superior labrum anterior-posterior (SLAP) lesions and 8 had posterior labral lesions, among the 10 labral lesion patients. This relationship was a significant among the groups $(\mathrm{p}<0.05)$. Entrapment neuropathy was observed in 6 cases in group 1. This relationship was also a significant difference among the groups $(\mathrm{p}<0.05)$.

There was a statistically significant difference due to ganglion cyst size in group 3 (p:0.001). Large-sized cysts were seen in group 3 . There was no significant difference in cyst size between 1 st group and 2nd group (p:0.933). There was a positive correlation between cyst size and the number of accompanying pathologies in the $1 \mathrm{st}$ and 2 nd groups (r:0.582, p:0.001). There was also a positive correlation between age and the number of accompanying pathologies (r:0.465, p:0.007). Spinoglenoid notch and paralabral ganglion cysts were most commonly accompanied by symptoms of shoulder pain and dysfunction. Spinogleniod notch ganglion cysts had paralysis symptoms associated with trap neuropathy in 5 cases (suprascapular nerve entrapment neuropathy causing isolated infraspinatus paralysis and concomitant external rotation limitation). Supra acromio-clavicular joint ganglion cysts all had complaints of shoulder swelling. Table 2 shows a comparison of symptoms which associated with ganglion cyst groups. 
Table 1. Comparison of demographic characteristics and accompanied pathologies of ganglion cyst groups (1st group; Spinoglenoid notch, 2nd group; paralabral, 3rd group; supra acromioclavicular joint patients).

\begin{tabular}{|c|c|c|c|c|}
\hline & $\begin{array}{c}1^{\text {st }} \text { group } \\
(n=15)\end{array}$ & $\begin{array}{c}2^{\text {nd }} \text { group } \\
(n=12)\end{array}$ & $\begin{array}{c}3^{\text {rd }} \text { group } \\
(n=5)\end{array}$ & $P$ values \\
\hline $\begin{array}{l}\text { Gender } \\
\text { (M:Meales, F:Females) }\end{array}$ & $8 \mathrm{M}: 7 \mathrm{~F}$ & $6 \mathrm{M}: 6 \mathrm{~F}$ & $2 \mathrm{M}: 3 \mathrm{~F}$ & $\begin{array}{l}X^{2}=0.267 \\
* P=0.875\end{array}$ \\
\hline Age Mean \pm SD (range) & $46.9 \pm 13$ years $(21-68)$ & $53.8 \pm 15$ years $(21-70)$ & $64 \pm 311$ years $(48-76)$ & $* * P=0.073$ \\
\hline Sizes Mean \pm SD (range) & $14.4 \pm 7 \mathrm{~mm}(7-31)$ & $15.3 \pm 7 \mathrm{~mm}(7-28)$ & $28.8 \pm 4 \mathrm{~mm}(24-35)$ & $* * P=0.001$ \\
\hline Rotator cuff pathologies n (\%) & $13(86.7)$ & $11(91.7)$ & $5(100)$ & $\begin{array}{l}\mathrm{X}^{2}=0.809 \\
* P=0.667\end{array}$ \\
\hline LHBT pathologies n (\%) & $3(20)$ & $9(75)$ & $2(40)$ & $\begin{array}{c}X^{2}=8.229 \\
* P=0.01\end{array}$ \\
\hline Labral lesions n (\%) & $2(13.3)$ & $10(83.3)$ & 0 & $\begin{array}{l}X^{2}=17.49 \\
* P<0.01\end{array}$ \\
\hline Entrapment neuropathy n (\%) & $6(40)$ & 0 & 0 & $\begin{array}{c}X^{2}=8.369 \\
* P=0.01\end{array}$ \\
\hline
\end{tabular}

The results are expressed as mean \pm standard deviation (SD), (range); LHBT - long head of the biceps tendon; $* P$ value shows the results of chi-square test; **P value shows the results of post hoc Tukey test.

Table 2. A comparison of the symptoms associated with ganglion cyst groups.

\begin{tabular}{|lcccc|}
\hline & $\begin{array}{c}\text { Pain } \\
\mathbf{n}(\boldsymbol{\%})\end{array}$ & $\begin{array}{c}\text { Dysfunction } \\
\mathbf{n}(\boldsymbol{\%})\end{array}$ & $\begin{array}{c}\text { Swelling in the shoulder } \\
\mathbf{n}(\boldsymbol{\%})\end{array}$ & $\begin{array}{c}\text { Paralysis symptoms } \\
\mathbf{n}(\boldsymbol{\%})\end{array}$ \\
\hline $\mathbf{1}^{\text {st }}$ group $(\mathbf{n = 1 5})$ & $15(100)$ & $12(80)$ & $1(6.6)$ & $6(40)$ \\
\hline $\mathbf{2}^{\text {nd }}$ group $(\mathbf{n = 1 2})$ & $12(100)$ & $12(100)$ & $1(8.3)$ & 0 \\
\hline $\mathbf{3}^{\text {rd }}$ group $(\mathbf{n = 5})$ & $4(80)$ & $2(40)$ & $5(100)$ & 0 \\
\hline
\end{tabular}
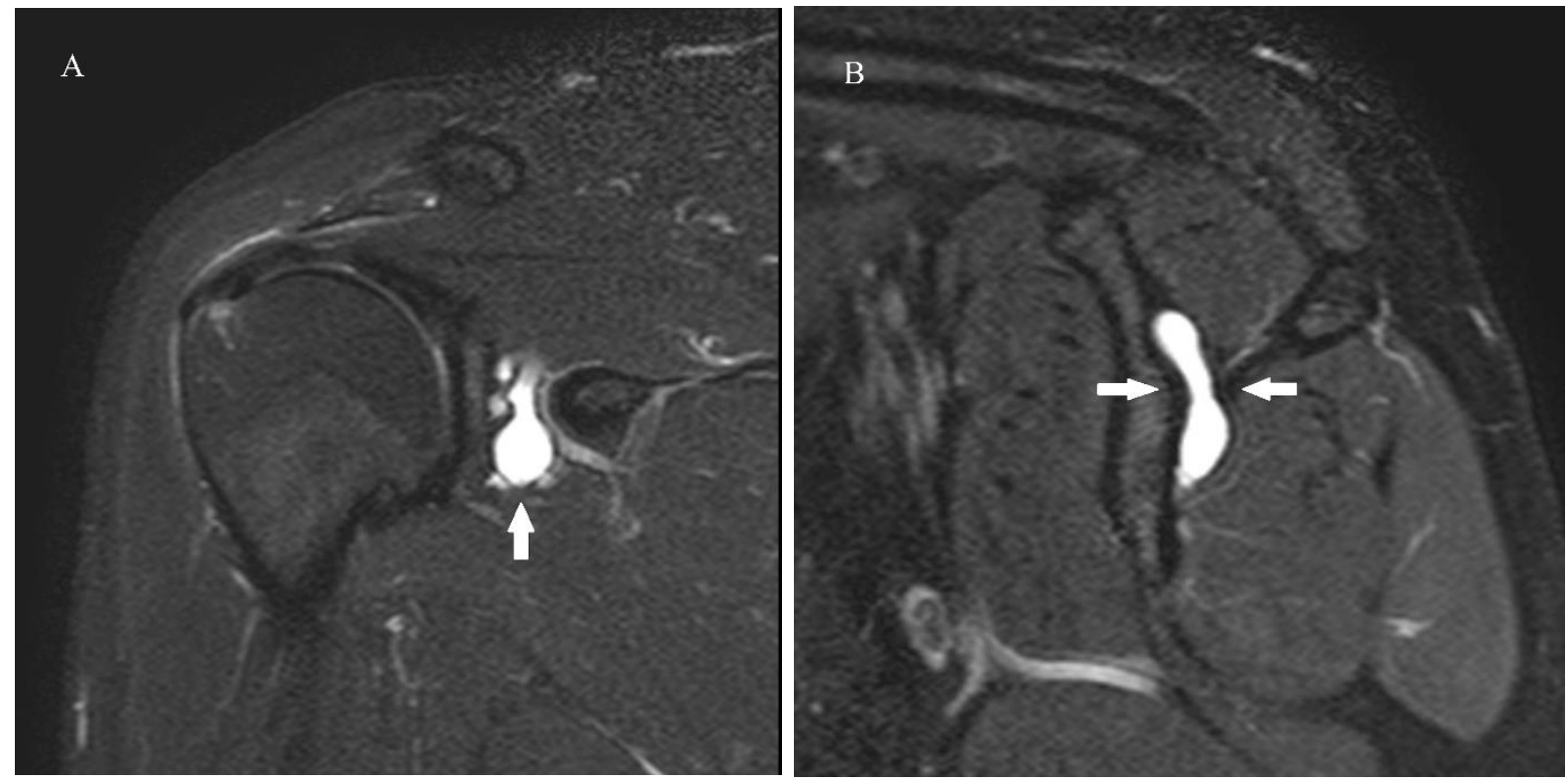

Figure 1. A 45-year-old male, T2-weighted coronal (A) sagittal (B) images, arrows indicate to spinoglenoid notch ganglion cyst. 


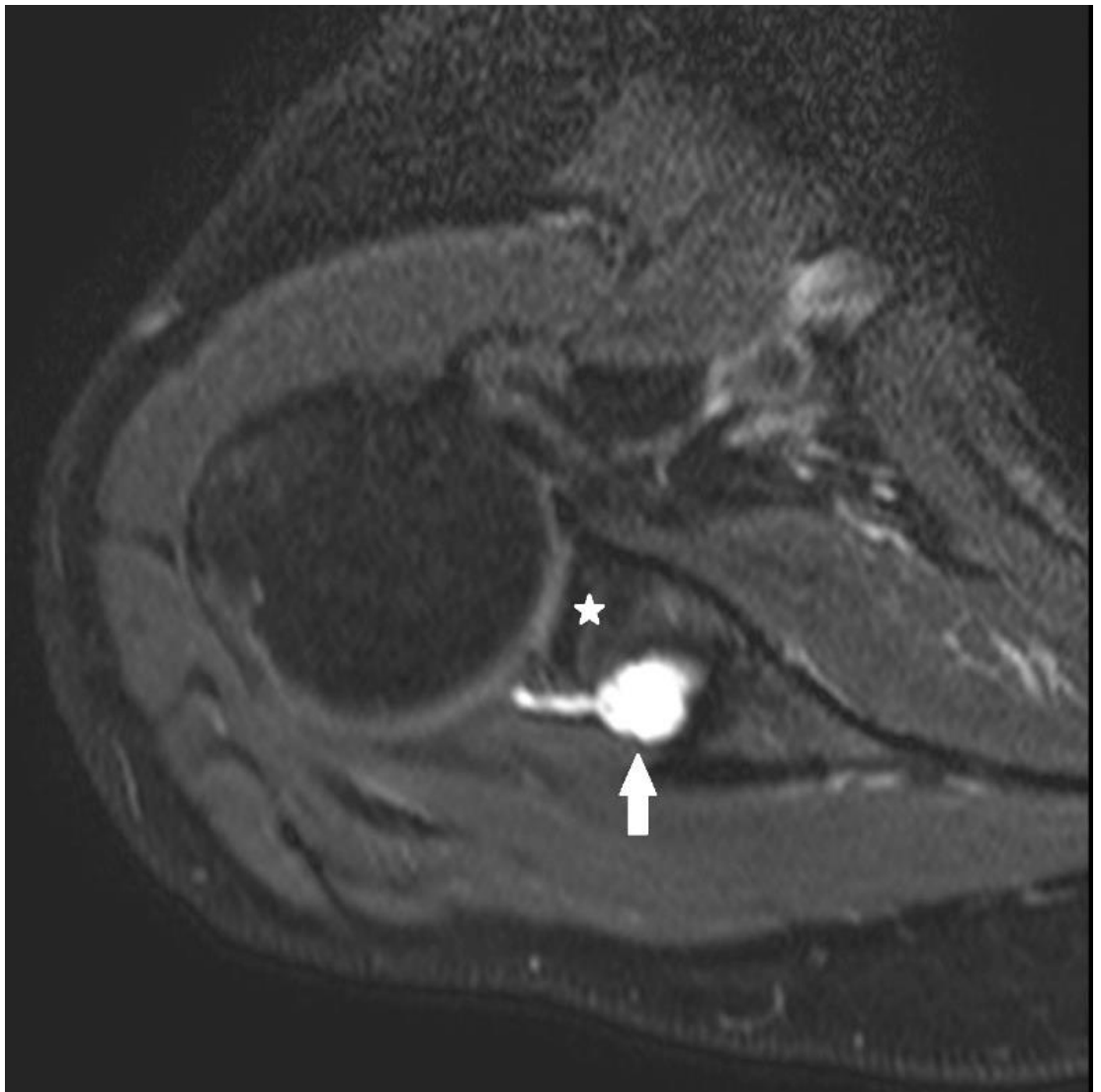

Figure 2. 65-year-old male, T2-weighted axial image, paralabral ganglion cyst (arrow, asterisk:glenoid).

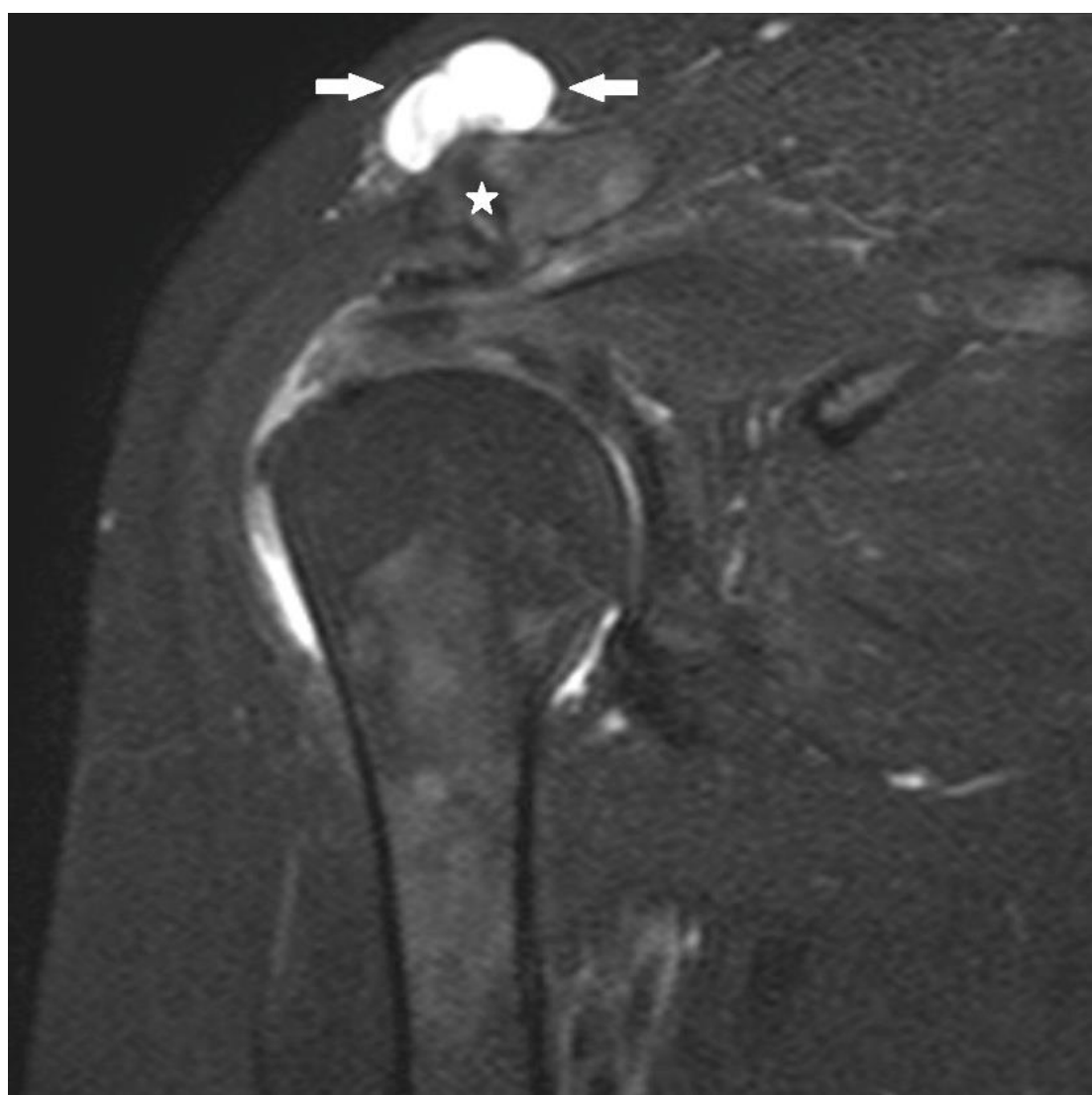

Figure 3. 71 years-old female, T2-weighted coronal image, supra acromioclavicular joint ganglion cyst (arrows, asterisk: acromioclavicular joint). 


\section{Discussion}

In our groups with ganglion cyst, we reveal that the rotator cuff tendon pathologies were accompanied with ganglion cyst. There was no a significant difference between the groups in terms of rotator cuff tendon pathologies $(p>0.05)$. However, entrapment neuropathy in group 1, the long head of the biceps tendon and labral lesions in group 2 had associations. This association was statistically significant among the groups $(\mathrm{p}<0.05)$.

The most commonly reported ganglion cysts in the literature are spinoglenoid notch, paralabral ganglion, and acromioclavicular joint cysts. For this reason, we included cysts in this localization in our study.

The differential diagnosis of ganglion cysts should include tuberculosis, rheumatoid tenosynovitis, lipoma, fibroma, osteoma, sarcoma and aneurysm. The definitive diagnosis is diagnosed by aspiration of bright, yellowish, dark, gelatinous material in needle aspiration. The diagnosis of ganglion cyst that is not complicated by MRI imaging method is easily diagnosed. In T2-weighted images, collections characterized by lobular, multiseptal, high signal increase are specific for ganglion cysts (2). In our study, diagnosis of ganglion cyst was made according to MRI findings.

Ganglion cysts on the shoulder are secondary clinical findings of compression effect, trapping and degeneration according to their localizations $(3,7-9,12)$. In our study, there was a positive correlation between cyst size and the number of accompanying pathologies in the 1st and 2nd groups (r:0.582, p:0.001). Presumably, in our cases, compression effect and degeneration developed as secondary tendon pathologies.

In some studies on supra-acromioclavicular joint ganglions associated with a rotator cuff tear have been reported (1315). Supra acromioclavicular ganglion cysts had rotator cuff tendon pathologies in all cases. Spinoglenoid notch ganglion cysts have been reported to be associated with suprascapular nerve compression and with SLAP lesions (16-18). In our cases, 6 (40\%) cases of trapping neuropathy and $2(13.3 \%)$ of SLAP lesions were detected in the ganglion cysts in the spinglenoid notch. The findings about paralabral ganglion cysts accompany with labral pathologies has also been reported previously $(6,11,16$, $19,20)$. In our study, labral lesions were detected in 10 $(83.3 \%)$ of the cases with paralabral ganglion cysts. It has been reported that ganglion cysts in the spinoglenoid notch compresses the suprascapular nerve and it's associated with SLAP lesions.

Treatment methods of ganglion cysts include surgical and non-surgical methods. In symptomatic cases, definitive treatment is surgical $(2,12,21,22)$. Surgical methods include; needle aspiration, arthroscopic and/or open surgical procedures $(9,12,22)$. The choice of surgical methods should be based on the localization of the cyst and the accompanying pathologies $(12,22)$. In our study, shoulder tendon pathologies and labral lesions which frequently accompanied shoulder ganglion cysts were investigated.
Limitations of the study are as follow. First, the lack of pathologic diagnosis and surgical results of ganglion cysts. Second, the number of cases is small. Third, the lack of studies on ganglion cysts in the shoulder according to previous literature. Fourth, retrospective evaluation of MRI images is the absence of different imaging techniques. It is necessary to study the comprehensive of radiological, surgical and pathological results together. Nevertheless, we believe that our study gives a different perspective to symptomatic ganglion cysts on the shoulder.

\section{Conclusion}

Rotator cuff tendon pathologies are commonly associated with all groups of shoulder ganglion cysts. In spinoglenoid notch ganglion cysts; trap neuropathy, in paralabral cysts; biceps tendon pathology and labral lesions show a significant association. In symptomatic cases with ganglion cyst in the shoulder in MRI, understanding ganglion cysts, knowing the pathologies accompanied with ganglion cysts may be useful in surgical planned cases.

\section{Acknowledgement: None}

Conflict of Interest: The authors declare no potential conflicts of interest with respect to the research, authorship, and/or publication of this article.

Author's Contributions: MHŞ: Research concept and design, data collecting, analysis and interpretation of data. Preparation of article and revisions. All authors approved the final version of the manuscript.

Ethical issues: All Authors declare, Originality and ethical approval of research. Responsibilities of research, responsibilities against local ethics commission are under the Authors responsibilities. The study was conducted under defined rules by the Local Ethics Commission guidelines and audits.

\section{References}

1. Nikas S, Drosos AA. Painless shoulder mass. Joint Bone Spine. 2015;4(82):286.

2. Akman S, Gür B, Sülün T, Aksoy B. A case of a ganglion cyst originating from the hip joint and surgical outcome. Acta orthopaedica et traumatologica turcica. 2002;36(1):76-8.

3. Cummins CA, Messer TM, Nuber GW. Current concepts reviewsuprascapular nerve entrapment. JBJS. 2000;82(3):415-24.

4. Gül M, Özkaya U, Parmaksızoğlu A, Sökücü S, Kabukçuoğlu Y. Ganglion kisti ve neden olduğu düşük ayak olgusu-olgu sunumu. Şeh Tıp Bülteni. 2008;42:25-7.

5. Erginer R, Oğüt T, Seyahi A, Dervişoğlu S. Suprascapular nerve entrapment by a ganglion cyst: a case report. Acta orthopaedica et traumatologica turcica. 2003;37(1):73-8.

6. Ho JC, lannotti JP. Glenoid labral tear associated paralabral ganglion cyst presenting as a neck mass: a case report. Journal of shoulder and elbow surgery. 2010;19(5):e10-e3.

7. Ji J-H, Shafi M, Lee $Y$, Kim D-J. Inferior paralabral ganglion cyst of the shoulder with labral tear-A rare cause of shoulder pain. Orthopaedics \& Traumatology: Surgery \& Research. 2012;98(2):1938. 
8. Sarman H, Celik M, Bala M. A rare cause of shoulder pain: Ganglion cyst of the acromioclavicular joint. Osteol Rheumatol Open J. 2016;1(1):20-2.

9. Seçkin MF, Kara A, Çelik H, Sönmez MM, Öztürk I. Nadir görülen bir omuz ağrısı nedeni: Spinoglenoid çentikte ganglion kisti.

10. Terabayashi N, Fukuta M, Ito Y, Takigami I, Nishimoto Y, Shimizu K. Shoulder impingement syndrome due to a ganglion cyst below the coracoacromial ligament: a case report. JBJS. 2011;93(8):e36.

11. Tirman P, Feller JF, Janzen DL, Peterfy CG, Bergman AG. Association of glenoid labral cysts with labral tears and glenohumeral instability: radiologic findings and clinical significance. Radiology. 1994;190(3):653-8.

12. Prasad NK, Spinner RJ, Smith J, Howe BM, Amrami KK, lannotti JP, et al. The successful arthroscopic treatment of suprascapular intraneural ganglion cysts. Neurosurgical focus. 2015;39(3):E11.

13. Hiller AD, Miller JD, Zeller JL. Acromioclavicular joint cyst formation. Clinical anatomy (New York, NY). 2010;23(2):145-52.

14. Singh RA, Hay BA, Hay SM. Management of a massive acromioclavicular joint cyst: the geyser sign revisited. Shoulder \& Elbow. 2013;5(1):62-4.

15. Tanaka S, Gotoh M, Mitsui Y, Shirachi I, Okawa T, Higuchi F, et al. A Case Report of an Acromioclavicular Joint Ganglion Associated with a Rotator Cuff Tear. The Kurume medical journal. 2017;63(1.2):2932.
16. Moore TP, Fritts HM, Quick DC, Buss DD. Suprascapular nerve entrapment caused by supraglenoid cyst compression. J Shoulder Elbow Surg. 1997;6(5):455-62.

17. Thompson RC, Jr., Schneider W, Kennedy T. Entrapment neuropathy of the inferior branch of the suprascapular nerve by ganglia. Clin Orthop Relat Res. 1982(166):185-7.

18. Wang YJ, Cui GQ. Arthroscopic excision of spinoglenoid notch cyst through two different approaches. Chin Med J (Engl). 2010;123(21):3154-6.

19. Kim DS, Park HK, Park JH, Yoon WS. Ganglion cyst of the spinoglenoid notch: comparison between SLAP repair alone and SLAP repair with cyst decompression. J Shoulder Elbow Surg. 2012;21(11):1456-63

20. Piatt BE, Hawkins RJ, Fritz RC, Ho CP, Wolf E, Schickendantz M. Clinical evaluation and treatment of spinoglenoid notch ganglion cysts. J Shoulder Elbow Surg. 2002;11(6):600-4.

21. Thomazeau H, Raoul T, Herve A, Basselot F, Common H, Ropars M. Are spinoglenoid ganglion cysts early markers of glenohumeral arthritis? J Shoulder Elbow Surg. 2016;25(7):1051-5.

22. Westerheide KJ, Karzel RP. Ganglion cysts of the shoulder: technique of arthroscopic decompression and fixation of associated type II superior labral anterior to posterior lesions. Orthop Clin North Am. 2003;34(4):521-8. 